\title{
A Y-ASSOCIATED ALLELE IS SHARED AMONG A FEW ETHNIC GROUPS OF ASIA
}

\author{
Shio Jean Lin, ${ }^{1,2}$ Karo TAnaKa, ${ }^{1, * *}$ William LeOnard, ${ }^{3}$ \\ Tudevdagviin GerelsaikHan, ${ }^{4}$ Bumbein DashnYam, ${ }^{4}$ \\ Sambuugiin Nyamkhishig, ${ }^{5}$ Akiko Hida, ${ }^{1}$ Yutaka Nakahori, ${ }^{1}$ \\ Keiichi Oмото, ${ }^{6}$ Michael H. Crawford,${ }^{7}$ and Yasuo NaKagome ${ }^{1, *}$ \\ ${ }^{1}$ Department of Human Genetics, School of International Health, University of Tokyo, \\ Bunkyo-ku, Tokyo 113, Japan \\ ${ }^{2}$ Department of Pediatrics, National Cheng Kung University Medical College, \\ Tainan, Taiwan \\ ${ }^{3}$ School of Human Biology, Guelph University, Guelph, Ontario, Canada \\ ${ }^{4}$ Department of Molecular Biology, Institute of Biotechnology, Academy of Sciences, \\ Ulanbator, Mongolia \\ ${ }^{5}$ Laboratory of Human Genetics, National Center of Anthropology, \\ National University of Medicine, Ulanbator \\ ${ }^{6}$ International Research Center for Japanese Studies, Kyoto, Japan \\ ${ }^{7}$ Department of Anthropology, University of Kansas, Lawrence, Kansas, U.S.A.
}

Summary In our previous study, both of Y-associated alleles, Y1 and $\mathrm{Y} 2$, were detected in Japanese and Koreans, but only the $\mathrm{Y} 1$ allele was detected in each of other populations including Chinese in both Beijin and Guangzhou areas, Caucasians, Africans, and Jewish. In the present study, these observations were extended to other ethnic groups in East Asia. Evenks in central Siberia and Khalkhs in Mongolia had only the Yl allele. On the other hand, two ethnic groups, Fo-lo and Hakka, in Taiwan had both of the Y1 and the Y2 alleles. Three of the eight Y2positive men, 2 Fo-lo and a Hakka, shared family name Chen. Both Hakka people and ancesters of Chen families could be traced to the Province of Henan in northern China in early 4th century. They arrived in Fujian/Guangdong area in the south-east China via various routes and then some of them migrated to Taiwan in the 18 th century. It is tempting to speculate that the Y2 allele may be originated from an ancestral population in Henan from which, Japanese, Koreans, and some of the

Received May 11, 1994; Revised version accepted June 20, 1994,

*To whom reprint request should be addressed.

**Present address: Department of Hygine and Public Health, School of Medicine, Teikyo University, Tokyo. 
Taiwanese diverged.

Key Words Y2 allele, RFLP, Y chromosome, Chinese, Japanese

\section{INTRODUCTION}

In 1989, some of the present authors described two novel RFLPs detected by $47 z(D X Y S 5)$ on the $X$ and the $Y$ chromosome (Nakahori et al., 1989). It was later found that both $\mathrm{Y} 1$ and $\mathrm{Y} 2$ alleles were detected in Japanese and Koreans, on the other hand, only the $\mathrm{Y} 1$ allele was detected in Chinese, Jews, Caucasians, and Africans (Nakagome et al., 1992). Both X1 and X2 alleles were detected in all the examined populations, but the frequency of the $\mathrm{X} 2$ allele was very low among Africans.

In the present study, these observations are extended to other Asian populations surrounding Japan and Korea to determine if any of them have the Y2 allele.

\section{MATERIALS AND METHODS}

Blood samples of unrelated males were collected in three areas, Tainan in Taiwan, Ulanbator in Mongolia, and the Evenki Okrug of central Siberia. The three areas are located on the south and north west of Japan/Korea (Fig. 1).

Samples obtained in Tainan consisted of 61 Fo-lo, 4 Hakka, and 7 "mainlander" males. The last group migrated from mainland China after 1949. None of the 72 males had known ancestor(s) related either to the Japanese or Koreans.

Eighty-five of 96 male samples obtained in Ulanbator belonged to Khalkh, a major ethnic group of Mongolia. In 80 of them, both parents were Khalkhs, and in 5, only the father belonged to Khalkh. Additional 11 males belonging to various minority groups were also included (4 Durvuds, 2 Darigangas, 2 Briads, 2 Zakhuchins, and 1 Torguud). In addition, blood samples of 8 Khalkh females were available.

Blood samples of 39 unrelated Evenk males and 24 unrelated females were obtained in both Surinda and Polingus village in a semi-autonomous territory, Evenki Okrug, of Central Siberia. They constitute a major tribe in that region of Siberia (Fig. 1).

Probe 47z(DXYS5) detects both Y- and X-associated polymorphisms. StuI digestion identifies a 2-allele polymorphism at $17 \mathrm{~kb}$ (Y1) or $5.3 \mathrm{~kb}$ (Y2). While, HindIII-TaqI double digestion reveals a 2-allele polymorphism at $3.2 \mathrm{~kb}(\mathrm{X} 1)$ and/ or $2.4 \mathrm{~kb}$ (X2) (Nakahori et al., 1989).

Extraction of DNA, electrophoresis, nick translation, hybridization, and other techniques were performed using standard methods. Four micrograms each of DNA samples were used in either of StuI or HindIII-TaqI double digestion. 


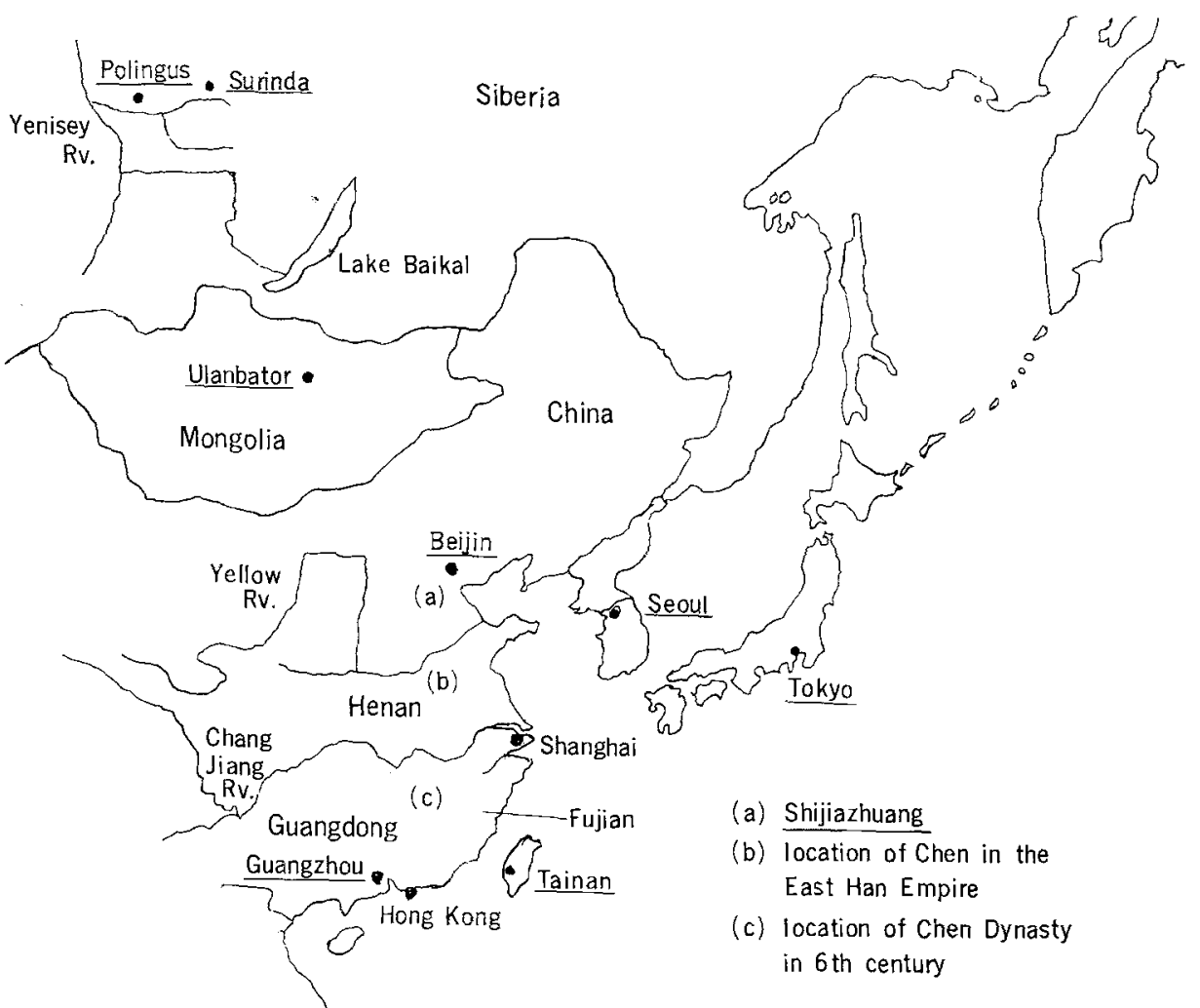

Fig. 1. Northeastern Asia. Samples obtained from 3 locations, Tokyo, Seoul, and Tainan, showed both $\mathrm{Y} 1$ and $\mathrm{Y} 2$ alleles. On the other hand, only the $\mathrm{Y} 1$ allele was observed in samples obtained in Evenki Okrug (Siberia), Ulanbator (Mongolia), Beijin, Shijiazhuang, and Guangzhou (China). Location of a small country called Chen within the East Han Empire (3rd century A.D.) and also Chen Dynasty in the 6th century are also indicated. Three provinces related to migration of both Chen families and Hakka; Henan, Guangdong, and Fujian, are also shown. A few additional landmarks, Yenisey River, Lake Baikal, Yellow River, Chang Jiang River, Shanghai, and Hong Kong are included.

\section{RESULTS}

Among the 61 Fo-lo males, 7 had the Y2 and 54 had the Y1 allele. One of 4 Hakka males had the Y2 and 3 had the Y1 allele. All the 7 mainlanders had the $\mathrm{Y} 1$ allele. As to the $\mathrm{X}$ polymorphism, all the 72 males had the $\mathrm{X} 1$ allele (Table 1). Family members were available of the only $Y 2$ positive Hakka male. Both his son and a grandson also had the Y2 allele. The propositus lived in Taiwan before the start (1895) of the Japanese rule.

Only the Y1 allele was observed in all of the 96 male samples from Mongolia including $85 \mathrm{Khalkhs}$ and 11 who belonged to various minority groups. Only 3 
Table 1. $\mathrm{Y}$ and $\mathrm{X}$ associated alleles detected by the probe $47 \mathrm{z}$.

\begin{tabular}{|c|c|c|c|c|}
\hline & Y1 & $\mathrm{Y} 2$ & $X 1$ & $\mathrm{X} 2$ \\
\hline Japanese ${ }^{a}$ & 49 & 19 & 203 & 66 \\
\hline Koreans a & 37 & 4 & 52 & 18 \\
\hline Chinese $\mathrm{B}$ a & 44 & 0 & 24 & 15 \\
\hline Chinese $\mathrm{G}^{\text {a }}$ & 26 & 0 & 27 & 20 \\
\hline Jews ${ }^{\text {a }}$ & 33 & 0 & 26 & 21 \\
\hline Caucasians ${ }^{a}$ & 26 & 0 & 41 & 15 \\
\hline Africans (U.S.A.) ${ }^{a}$ & 21 & 0 & 51 & 2 \\
\hline Evenks ${ }^{b}$ & 37 & 0 & 28 & 18 \\
\hline Khalkhs b & 85 & 0 & 12 & 7 \\
\hline Misc. Mongol b & 11 & 0 & - & - \\
\hline Fo-los b & 54 & 7 & 61 & 0 \\
\hline Hakkas b & 3 & 1 & 4 & 0 \\
\hline Chinese $\mathbf{T} \cdot$ & 7 & 0 & 7 & 0 \\
\hline
\end{tabular}

a Modified from Nakahori et al. (1989) and Nakagome et al. (1992). Chinese B, G, and T were collected in Beijin, Guangzhou, and Tainan, respectively. b Present results. Khalkhs and misc. Mongol were collected in Ulanbator and the latter represents mixture of various ethnic groups (see text). Fo-los, Hakkas, and Chinese $T$ were obtained in Taiwan (see also text).

of Khalkh males were available for X-polymorphism study because of limited amount of DNA. All had the X1 allele. Out of 8 Khalkh females, 2 had only the $X 1$ allele (genotype: $X 1, X 1), 5$ had both $X 1$ and $X 2(X 1, X 2)$, and one had only $\mathrm{X} 2(\mathrm{X} 2, \mathrm{X} 2)$. When both males and females were combined, number of alleles were twelve $\mathrm{X} 1$ and seven $\mathrm{X} 2$.

As to Evenks, all the 37 males had the Y1 allele. In 2, results were not obtained because of technical problems. Twenty-three of 24 female samples were analyzed and 10 had X1, 8 had both X1 and X2, and 5 had X2. No male sample was available for $\mathrm{X}$-polymorphism study. Number of $\mathrm{X} 1$ and $\mathrm{X} 2$ alleles were 28 and 18 , respectively (Table 1 ).

\section{DISCUSSION}

In our previous study, we showed that 19 of $68(28 \%)$ Japanese and 4 of 41 $(10 \%)$ Korean males had the Y2 allele (Nakahori et al., 1989; Nakagome et al., 1992). None of the Chinese, Jewish, Caucasian, and African males had the Y2 allele and all had the $Y 1$ allele. Chinese samples were collected either in Beijin and Shijiazhuang near Beijin (Chinese B, 44 males) or in Guangzhou (Chinese G, 26 males) each locating northern and southern parts of China. Blood samples were collected from "normal" males and presumably they belonged to the Han, the major ethnic group in China. However, no further effort was made to trace 
their ethnic origins.

In the present study, no Y2 allele was observed in either the Evenks of Siberia or the Khalkh of Mongolia. Blood samples of Evenks were obtained in Evenki Okrug of central Siberia. However, Evenks also live in various regions of east Siberia. Evenks and Khalkhs together with those in northern and southern China represent major ethnic groups surrounding Japan and Korea. It is surprising that none of these ethnic groups shared the Y2 allele with Japanese and Koreans. On the other hand, some of male samples collected in Taiwan had the Y2 allele.

One of the Y2-positive Fo-lo family kept a detailed record of their family. Their ancestor moved from Fujian in mainland to Taiwan 7 generations ago during the Chin Dynasty in the 18th century. According to family tradition, their ancestors lived in Henan, a long time ago.

According to Lo (1950), Hakka lived in Henan and southern parts of Shanxi near the Yellow River. Because of the wars which prevailed in the area at around early 4th century (Eberhard, 1980), many of the Hakka left the area, headed south and south east and settled along the Chang Jiang (Yangtze) River from Hubei to Anhui. Around the end of 9th century, they were further pushed down to Ji'an and the border area between Guangdong and Fujian. During the 12th to 17th centuries, they were dispersed by the pressure from the north including that of Mongol, and settled in north and east parts of Guangdong and also in Guangxi. The final migration occurred after the 17 th century when Manchurians established the Chin Dynasty of Beijin in 1644. They dispersed to Hunan, Sichuan, Guangxi, coastal parts of Guangdong and Taiwan (Lo, 1950).

Fo-lo means people who came from Fujian and may not represent a specific ethnic group. On the other hand, out of 8 Y2-positive men, 3 had family name Chen, 2 of 7 Fo-lo and a Hakka man. Chen is a rather popular name in China and constituted about $12 \%$ of Taiwanese families in the 1930s (Chen, 1979). Chinese have been well known for their extreme nepotism. A large family either migrate together or a band of relatives, remote or close, follows a successful pioneer. Chen families in Taiwan except for Hakka may, in fact, originated from a single or a small number of families.

During the Han Dynasty which started 206BC and then lasted for some 400 years, the use of family name spread throughout the Empire (Eberhart, 1980). According to Chen (1979), Chen families lived in Henan, south of the Yellow River, from the age of mythology to the early 4th century. On the map of the East Han Empire, which succeeded the Han, a small country consisted in the area with the name of Chen. The Chens left the area and moved south as did the Hakka. They migrated further south and established the Chen Dynasty (557-588AD) in proximity to Ganzhou, which is located north of Guangdong. When Tang Dynasty was established in 618AD in north and expanded to south, they dispersed to various parts of Fujian. At about the same time as Hakka, some of them reached Taiwan.

Chen families originated in Henan before 4th century as did Hakka, In the 
present study, the number of Hakka males examined are very small and no conclusion can be drawn as to whether the Y2 allele is common among Hakka. However, it is astonishing that ancestors of both Hakka and Chen families lived in Henan until early 4th century. As to the Y2 allele found in both Japanese and Koreans, we are not yet sure whether it was originated in this area. Further studies on Hakka and also on other ethnic groups who lived in the Henan area before 3rd century, if we can identify them, are of interest and may have relevance to the origin of both Japanese and Koreans.

As to $\mathrm{X}$ alleles, both $\mathrm{X} 1$ and $\mathrm{X} 2$ alleles were observed in Caucasians, Jews, and a few ethnic groups in Asia (Nakagome et al., 1992). A limited number of the X2 allele detected in Africans in the United States, could have been caused by a gene flow from Caucasians to Africans. Native African population may lack the allele, although, further studies are needed. The lack of the X2 allele in Taiwanese may be explained by bottleneck effects and thus does not necessarily mean the lack of the X2 allele in their ancestral populations in Fujian or Henan. It, by no means, proves genetic differences among the ancestral populations of the Y2-positive groups, Japanese, Koreans, and Taiwanese. Study of other ethnic groups in Taiwan, including aboriginal tribes, are of interest.

Acknowledgments We are grateful to Drs. Momoki Hirai, Shinji Harihara, and Takafumi Ishida, Department of Anthropology, Graduate School of Sciences, University of Tokyo, for their valuable contribution in the collection of blood specimens in Mongolia. Thanks are also due to Mrs. Gui Guijun, a graduate student of University of Tokyo, who was helpful in tracing Chinese history. Supported in part by grants from the Ministry of Education, Science and Culture, the Ministry of Health and Welfare of Japan, and the grant BSR-910571, form the National Science Foundation, U.S.A. The probe $47 \mathrm{z}$ was provided by J. Weissenbach, Paris.

\section{REFERENCES}

Chen SL (1979): Population and social evolution in Taiwan (in Chinese). Lien Jin Publ., Taipei

Eberhard W (1980): Geschichte Chinas (Translated into Japanese by Ohmuro M and Matsudaira I), Alfred Kroner Verlag, Stuttgart, 1980

Lo SL (1950): On the oirgin of Hakka (in Chinese). Hong Kong Chong Zhen Association, Hong Kong

Nakagome Y, Young SR, Akane A, Numabe H, Jin DK, Yamori Y, Seki S, Tamura T, Nagafuchi S, Shiono H, Nakahori Y (1992): A Y-associated allele may be characteristic of certain ethnic groups in Asia. Ann Hum Genet 56: 311-314

Nakahori Y, Tamura T, Yamada M, Nakagome Y (1989): Two 47z [DXYS5] RFLPs on the X and $\mathrm{Y}$ chromosome. Nucleic Acids Res 17: 2152 